\title{
The origin of widespread species in a poor dispersing lineage (diving beetle genus Deronectes)
}

\author{
David García-Vázquez ${ }^{1}$, Ignacio Ribera ${ }^{\text {Corresp. } 1}$ \\ ${ }^{1}$ Institute of Evolutionary Biology (CSIC-Universitat Pompeu Fabra), Barcelona, Spain \\ Corresponding Author: Ignacio Ribera \\ Email address: ignacio.ribera@ibe.upf-csic.es
}

In most lineages most species have restricted geographic ranges, with only few reaching widespread distributions. How these widespread species reached their current ranges is an intriguing biogeographic and evolutionary question, especially in groups known to be poor dispersers. We reconstructed the biogeographic and temporal origin of the widespread species in a lineage with particularly poor dispersal capabilities, the diving beetle genus Deronectes (Dytiscidae). Most of the ca. 60 described species of Deronectes have narrow ranges in the Mediterranean area, with only four species with widespread European distributions. We sequenced four mitochondrial and two nuclear genes of 297 specimens of 109 different populations covering the entire distribution of the four lineages of Deronectes including widespread species. Using Bayesian probabilities with an a priori evolutionary rate we performed (1) a global phylogeny/phylogeography to estimate the relationships of the main lineages within each group and root them, and (2) demographic analyses of the best population coalescent model for each species group, including a reconstruction of the geographical history estimated from the distribution of the sampled localities. We also selected 56 specimens to test for the presence of Wolbachia, a maternally transmitted parasite that can alter the patterns of mtDNA variability. All species of the four studied groups originated in the southern Mediterranean peninsulas and were estimated to be of Pleistocene origin. In three of the four widespread species the central and northern European populations were nested within those in the northern areas of the Anatolian, Balkan and Iberian peninsulas respectively, suggesting a range expansion at the edge of the southern refugia. In the Mediterranean peninsulas the widespread European species were replaced by vicariant taxa of recent origin. The fourth species ( $D$. moestus) was proven to be a composite of unrecognised lineages with more restricted distributions around the Western and Central Mediterranean. The analysis of Wolbachia showed a high prevalence of infection among Deronectes, especially in the $D$. aubei group, where all sequenced populations were infected with the only exception of the Cantabrian Mountains, the westernmost area of distribution of the lineage. In this group there was a phylogenetic 
incongruence between the mitochondrial and the nuclear sequence, although not clear pattern links this discordance to the Wolbachia infection. Our results suggest that in different glacial cycles populations that happened to be at the edge of the newly deglaciated areas took advantage of the optimal ecological conditions to expand their ranges to central and northern Europe. Once this favourable ecological window ended populations become isolated, resulting in the presence of closely related but distinct species in the Mediterranean peninsulas. 
1 The origin of widespread species in a poor dispersing lineage (diving beetle

2 genus Deronectes)

3

4

5 David García-Vázquez and Ignacio Ribera

6

7 Institute of Evolutionary Biology (CSIC-Universitat Pompeu Fabra), Barcelona, Spain

8

9 Author for correspondence: Ignacio Ribera (e-mail address: ignacio.ribera@ibe.upf-csic.es)

10

11 Running title: Origin of Deronectes widespread species 


\section{Abstract}

13 In most lineages most species have restricted geographic ranges, with only few reaching 14 widespread distributions. How these widespread species reached their current ranges is an 15 intriguing biogeographic and evolutionary question, especially in groups known to be poor 16 dispersers. We reconstructed the biogeographic and temporal origin of the widespread species in 17 a lineage with particularly poor dispersal capabilities, the diving beetle genus Deronectes 18 (Dytiscidae). Most of the ca. 60 described species of Deronectes have narrow ranges in the 19 Mediterranean area, with only four species with widespread European distributions. We sequenced four mitochondrial and two nuclear genes of 297 specimens of 109 different populations covering the entire distribution of the four lineages of Deronectes including widespread species. Using Bayesian probabilities with an a priori evolutionary rate we performed (1) a global phylogeny/phylogeography to estimate the relationships of the main lineages within each group and root them, and (2) demographic analyses of the best population coalescent model for each species group, including a reconstruction of the geographical history estimated from the distribution of the sampled localities. We also selected 56 specimens to test for the presence of Wolbachia, a maternally transmitted parasite that can alter the patterns of mtDNA variability. All species of the four studied groups originated in the southern Mediterranean peninsulas and were estimated to be of Pleistocene origin. In three of the four widespread species the central and northern European populations were nested within those in the northern areas of the Anatolian, Balkan and Iberian peninsulas respectively, suggesting a range expansion at the edge of the southern refugia. In the Mediterranean peninsulas the widespread European species were replaced by vicariant taxa of recent origin. The fourth species (D. moestus) was proven to be a composite of unrecognised lineages with more restricted distributions around the Western and Central Mediterranean. The analysis of Wolbachia showed a high prevalence of infection among Deronectes, especially in the D. aubei group, where all sequenced populations were infected with the only exception of the Cantabrian Mountains, the westernmost area of distribution of the lineage. In this group there was a phylogenetic incongruence between the mitochondrial and the nuclear sequence, although not clear pattern links this discordance to the Wolbachia infection. Our results suggest that in different glacial cycles populations that happened to be at the edge of the newly deglaciated areas took advantage 
43 this favourable ecological window ended populations become isolated, resulting in the presence 44 of closely related but distinct species in the Mediterranean peninsulas. 45 


\section{INTRODUCTION}

47 The geographic range of the species is a fundamental trait in ecology and biogeography (Brown

48 \& Lomolino, 1998). There have been many hypotheses put forward by ecologists,

49 biogeographers or evolutionary biologists to explain geographic ranges (see e.g. Brown, 1995 or

50 Gaston, 2003 for reviews), such as differences in niche breadth, body size, population

51 abundance, environmental variability, colonization and extinction dynamics, and dispersal ability

52 among others (Stevens, 1989; Brown, 1995; Gaston, 2003), but there is still a lack of

53 understanding of the evolutionary dynamics of geographical ranges. Thus, and although the

54 ecological and biogeographic context in which species evolve are known to determine their

55 range sizes (Böhning-Gaese, 2006), there are multiple cases of closely related species, sharing a

56 common phylogenetic history and with a similar biology and ecology, that have nonetheless

57 extreme differences in the size of their geographical range (Lester et al., 2007).

58 In freshwater species, one of the most general and robust associations is that of habitat

59 stability and geographic range (Ribera, 2008; Dijkstra, Monaghan \& Pauls, 2014). Species living

60 in standing waters tend to have better dispersal abilities than species living in running waters,

61 due to the shorter geological duration of their habitats. Running water species have on average

62 smaller geographic ranges and a lower gene flow between populations (Ribera, 2008; Abellán,

63 Millán \& Ribera, 2009). Range size is also strongly correlated with extinction probability

64 (Jablonsky, 1987), and high probabilities of extinction have been linked with narrow

65 geographical ranges in several taxa (see e.g. Hansen, 1980 for marine invertebrates, Purvis et al.,

662000 for mammals, or Rosenfield, 2002 for freshwater fishes). This raises the question of how

67 lineages with a predominance of running water species, and thus on average smaller geographic

68 ranges, can persist over long evolutionary periods. It must be noted here that while among

69 standing water species the frequency of species with small ranges is expected to be low, within

70 running water lineages it is not rare to find widespread species (Ribera \& Vogler, 2000). This is

71 likely due to the asymmetry in the habitat constraints: standing water species have to migrate

72 when their habitat disappears, but the higher stability of running water habitats means that

73 species in them do not need to disperse. Nevertheless, they tend to lose dispersal capabilities,

74 likely due to their associated cost (see Ribera, 2008 for a review), although in some

75 circumstances running water species seem to be able to disperse and reach widespread

76 distributions. These few widespread species may be of disproportionate importance, as potential 
77 sources of new species ("diversity pumps", Ribera et al., 2011), but there is very few data on

78 what makes a species in a clade of poor dispersers able to expand its range, or in what

79 circumstances.

80 A common pattern among many lineages with abundance of species with restricted

81 geographic ranges within the Mediterranean area is the presence of one (or few) species with a

82 widespread distribution including parts of central and northern Europe. These northern

83 populations should have a recent origin, as most of central and northern Europe was glaciated or

84 with permafrost during the Last Glacial Maximum, when the European ice sheet extended north

85 of $52^{\circ} \mathrm{N}$ and the permafrost north of $47^{\circ} \mathrm{N}$ (Dawson, 1992). It is thus clear that some species

86 were able to expand their ranges in a short time, as they could not have survived on the ice sheet.

87 We study the origin and phylogeography of the European widespread species in one of

88 these running water lineages, the diving beetle genus Deronectes Sharp (family Dytiscidae).

89 With c. 60 described species (Nilsson \& Hájek, 2015), Deronectes is the largest clade of

90 Palaearctic diving beetle entirely confined to running waters. It has a predominantly

91 Mediterranean distribution, ranging from North Africa and the Iberian Peninsula over most parts

92 of Europe and the Middle East, with some species reaching central Asia (Nilsson, 2001). The

93 genus has many narrow range Mediterranean species, including some island endemics, but also a

94 few species widespread in central and northern Europe, showing their potential for range

95 expansion. A recent molecular phylogeny of the genus (García-Vázquez et al., 2016) supported

96 the existence of two main lineages, mostly corresponding to species with a western or eastern

97 distribution. The widespread European species were also shown to be of Pleistocene origin, in

98 agreement with other works with the genus (Ribera, Barraclough \& Vogler, 2001; Ribera, 2003;

99 Ribera \& Vogler, 2004; Abellán \& Ribera, 2011).

100 Our main objective here is to reconstruct in detail the temporal and geographic origin of

101 the widespread European species of Deronectes, using molecular data from a comprehensive

102 sampling of them and their closest relatives, covering their entire distributions.

103

104 MATERIAL AND METHODS

105 Taxonomic background

106 Four species of Deronectes have widespread European distributions. Three of them are

107 found in central and northern Europe, i.e areas strongly affected by the last glacial cycle: (1) $D$. 
108 aubei (Mulsant), (2) D. latus (Stephens) and (3) D. platynotus (Germar). The fourth, D. moestus

109 (Fairmaire), is distributed along the western Mediterranean from the Maghreb to the Balkans,

110 although with high intraspecific variation, according to the preliminary results of García-

111 Vázquez et al. (2016). All four belong to different species groups within the genus, as defined by

112 García-Vázquez et al. (2016).

113 (1) The D. aubei group includes three species, one of them divided in two subspecies.

114 The widespread D. aubei includes D. a. aubei from the Alps and surrounding areas, reaching

115 southern Germany (Black forest) in the north, and D. a. sanfilippoi Fery \& Brancucci distributed

116 from the Cantabrian mountains in NW Spain to southern France (Pyrenees). The other two

117 species are D semirufus (Germar), from the Alps Maritims to Sicily, and D. delarouzei

118 (Jacquelin du Val) in the Pyrenees (Fery \& Brancucci, 1997) (Fig. 1). García-Vázquez et al.

119 (2016) found incongruence between mitochondrial and nuclear data within the D. aubei group.

120 According to the mitochondrial sequence, the two subspecies of $D$. aubei were recovered as

121 paraphyletic and respectively sisters to the geographically closest species of the group: one clade

122 was distributed west of the Rhone river, including D. a. sanfilippoi and D. delarouzei, and

123 another east of the Rhone, with D. a. aubei and D. semirufus. On the contrary, the nuclear

124 sequence recovered a monophyletic $D$. aubei as sister to the other two species of the group $(D$.

125 delarouzei and D. semirufus).

126 (2) The D. latus group, within the eastern Mediterranean lineage of Deronectes, includes

127 four species. Deronectes latus is the most widespread species of the genus, occupying large areas

128 of Europe north of the Pyrenees and the Apennines, reaching the British Isles and Scandinavia.

129 On the contrary, the other three species have restricted distributions in the southern peninsulas:

130 D. toledoi Fery, Erman \& Hosseinie in northeastern Turkey; D. angusi Fery \& Brancucci in

131 northwestern Spain; and D. angelinii Fery \& Brancucci, the only Italian endemic of the genus,

132 from the Apennines to Sicily, including the island of Elba (see Fig. 1 for the distribution of each

133 species). The entire group was reconstructed as having an origin in the Anatolian peninsula, from

134 were expanded first to Italy and the Balkan Peninsula and subsequently to the Iberian Peninsula

135 and central and northern Europe (García-Vázquez et al., 2016).

136 (3) The D. platynotus group, in the western clade of Deronectes, comprises two species,

137 with two subspecies each. Deronectes platynotus includes the widespread D. p. platynotus,

138 distributed from the Balkans and northern Greece to central Europe, and the subspecies D. $p$. 
139 mazzoldi Fery \& Brancucci, from northern Greece. The second species, the NW Iberian endemic 140 D. costipennis Brancucci, includes D. c. costipennis from Portugal and the extreme NW Iberia, 141 and D. c. gignouxi Fery \& Brancucci, from the Cantabrian region (Fery \& Brancucci, 1997) (Fig. $1421)$.

(4) The D. moestus group includes the fourth of the widespread European species of the 144 genus, D. moestus, distributed from the Maghreb and the Iberian Peninsula to the Balkans 145 through southern France, Italy and Sicily, together with other western Mediterranean species. 146 According to the results of García-Vázquez et al. (2016) D. moestus as currently understood is 147 paraphyletic, and includes the Mallorcan endemic D. brannani (Schauffus). The two recognised 148 subspecies of D. moestus, D. m. moestus from Corsica and Sardinia and D. m. inconspectus 149 (Leprieur) from the continent, were not recovered as respectively monophyletic. Here we studied 150 the species D. moestus sensu lato plus D. brannani, what we call the D. moestus complex (Fig.

151 1). The species D. perrinae Fery \& Brancucci, from Algeria and Tunisia, is morphologically 152 very close to $D$. moestus, and probably should be included in this complex, although no 153 specimens could be obtained for study.

154

\section{Taxon sampling}

156 We studied a total of 296 specimens of 109 populations (with a maximum of 5 specimens per 157 population) of all species of the four studied lineages of Deronectes, of which 23 specimens were 158 previously used by García-Vázquez et al. (2016) (Table S1). We aimed to cover the full 159 geographic range of the studied species, in particular potential cryptic refuge areas (in the sense 160 of Homburg et al., 2013) at the margins of the Alps and neighbouring mountain ranges (such as 161 the Black Forest), or areas not included in previous works (e.g. Sicily or French Massif Central 162 for the species of the D. aubei group).

163

164 DNA extraction and sequencing

165 Specimens were collected and preserved in absolute ethanol directly in the field. We extracted 166 the DNA non-destructively with commercial kits (mostly "DNeasy Tissue Kit", Qiagen GmbH, 167 Hilden, Germany and "Charge Switch gDNA Tissue Mini Kit", Invitrogen, Carlsbad, CA, USA) 168 following the manufacturer's instructions. Specimens and DNA extractions are kept in the 169 collections of the Institut de Biología Evolutiva, Barcelona (IBE), Museo Nacional de Ciencias 
170 Naturales, Madrid (MNCN) and Natural History Museum, London (NHM).

171 We obtained seven gene fragments from six different genes (four mitochondrial and two

172 nuclear) in five different amplification reactions (see Table S2 for primers and typical

173 sequencing reactions): 1) 5'end of the Cytochrome Oxidase Subunit 1 gene (the barcode

174 fragment, Hebert et al., 2003, COI-5'); 2) 3'end of Cytochrome Oxidase Subunit 1 (COI-3'); 3)

1755 'end of 16S rRNA plus tRNA transfer of Leucine plus 3'end of NADH subunit 1 (nad1) (16S);

176 and internal fragments of the nuclear genes 4) Histone $3(\mathrm{H} 3)$ and 5) Wingless (Wg). The nuclear

177 markers were only used in representative specimens according to geographical (one specimen

178 per population) and topological criteria. For each amplification reaction we obtained both

179 forward and reverse sequences. In some specimens, and due to difficulties of amplification, we

180 used internal primers for the fragment COI-3', obtaining two fragments of $400 \mathrm{bp}$ each. The

181 obtained products were purified by standard ethanol precipitation and sent to external facilities

182 for sequencing after purification (LMU Genomics Service Unit, Martinsried, Germany). DNA

183 sequences were assembled and edited using the GENEIOUS 6 software (Biomatters Ltd,

184 Auckland, New Zealand). New Deronectes sequences (a total of 791) have been deposited in

185 GenBank with accession numbers LT601818-LT602609, and Wolbachia sequences (23) with

186 numbers LT602610-LT602633 (Table S1).

187

188 Phylogenetic and phylogeographic analyses

189 Edited sequences were aligned with MAFFT v.6 using the G-INS algorithm and default values

190 for other parameters (Katoh \& Toh, 2008). We employed six partitions corresponding to the gene

191 fragments COI-5', COI-3', 16S rRNA+tRNA-Leu, nad1, H3 and Wg, and used Partition Finder

192 1.1.1 (Lanfear et al., 2014) to estimate the best partitioning scheme (each gene separately or

193 combining genes in a partition by codons) and the evolutionary model that best fitted the data for

194 each partition separately, using the AIC (Akaike Information Criterion) as selection criteria. We

195 performed two types of analyses using different datasets: (1) a global phylogeny/phylogeography

196 to estimate the relationships of the main lineages within each group and root them; and (2)

197 demographic analyses of the best population coalescent model for each group, including a

198 reconstruction of the geographical history estimated from the distribution of the sampled

199 localities. 
For the global phylogeny/phylogeography we first selected one specimen per population

201 to estimate the general topology of the four lineages within the wider genus Deronectes,

202 employing Bayesian methods implemented in BEAST 1.8 (Drummond \& Rambaut, 2007), using

203 as outgroups 18 species of Deronectes in other species groups. We rooted the trees in the

204 separation between the western and eastern clades of the genus, following García-Vázquez et al.

205 (2016). For the analysis we implemented the closer available evolutionary model to those

206 selected by Partition Finder and the best partitioning scheme, including both mitochondrial and

207 nuclear markers. As there are no fossils or unambiguous biogeographic events that could be used

208 to calibrate the phylogeny of Deronectes (García-Vázquez et al., 2016) we applied an a-priori

209 rate of 0.013 substitutions/site/MY (standard deviation 0.002 ) for protein coding genes and

2100.0016 substitutions/site/MY (standard deviation 0.0002 ) for $16 \mathrm{~S}$, obtained in a related group

211 (family Carabidae) for the same mitochondrial genes (Andujar, Serrano \& Gómez-Zurita, 2012).

212 As there are no reliable estimations of the evolutionary rate of the nuclear genes we applied an

213 uniform flat prior (from 0 to infinite). We used an uncorrelated lognormal relaxed clock, a Yule

214 speciation model and executed two independent analyses with the same settings, running 100

215 million generations (saving trees every 5000) or until they converged and the number of trees

216 was sufficient according to Effective Sample Size (ESS) values, as measured with TRACER

217 V1.6 (Drummond \& Rambaut, 2007). The majority rule consensus tree of the two runs was

218 compiled with Tree Annotator v1.8 (Drummond \& Rambaut, 2007). To test for potential

219 discordances among the different markers we also analysed separately the mitochondrial and

220 nuclear data. We applied the same settings as the combined analysis but, to estimate the

221 divergence dates among species, we established as a prior for the root of the tree a normal

222 distribution with average $14 \mathrm{Ma}$ and a standard deviation of 0.1 , according to the results obtained

223 in García-Vázquez et al. (2016).

224 For the demographic analyses we used all sequenced specimens from all populations to

225 estimate, for each of the four groups separately, the demographic model (constant, logistic,

226 expansion or exponential) that best fitted the data. Previously, we tested the adjustment to a strict

227 molecular clock and used the best clock model in the coalescent analyses. We used the

228 mitochondrial sequence only and no outgroups, with a GTR $+\mathrm{I}+\mathrm{G}$ evolutionary model and the

229 same settings used in the analysis of the topology. For model selection of the molecular clock

230 and coalescent analyses we used the modified Akaike information criterion (AICM) with 
231 moments estimator (Baele et al., 2012), as implemented in TRACER v1.6, with 1000 bootstrap

232 replicates. We also computed Bayesian skyline plots for each group to reconstruct the variation

233 of the effective population sizes with time.

$234 \quad$ Using the best clock and demographic models as selected above, and after excluding

235 specimens from the same locality with repeated haplotypes, we reconstructed the

236 phylogeographic history of each group in BEAST using the coordinates of each locality as a

237 quantitative trait (Lemey et al., 2009). We excluded outgroups, but included the nuclear markers

238 in the analyses. We overlaid the reconstructed coordinates of the nodes of the phylogeography of

239 each group, as obtained with BEAST and SPREAD v1.0.6 (Bielejec et al., 2011), in Google

240 Earth (http://earth.google.com), allowing the reconstruction through time of the history of each

241 lineage, from the origin until the current distribution.

242

\section{Wolbachia detection}

244 The incongruence between the mitochondrial and the nuclear data in the D. aubei group noted by

245 García-Vázquez et al. (2016) raised the possibility that specimens could be infected with

246 Wolbachia, a maternally transmitted parasite that can alter the patterns of mtDNA variability

247 (Jiggins, 2003). We thus tested for the presence of Wolbachia in 56 selected specimens (see

248 Table S1) of the four studied groups of Deronectes, focusing on the species of the D. aubei

249 group.

250 We used specific primers for the wsp gene, amplifying a $632 \mathrm{bp}$ fragment. A $3 \mu \mathrm{l}$ sample

251 of the PCR reaction mixture was electrophoresed with a $100 \mathrm{bp}$ DNA ladder on 1\% agarose gel

252 to determine the presence and size of the amplified DNA bands, that were visualized by Sybr-

253 Safe staining. A selection of positive PCR's were purified by standard ethanol precipitation and

254 sent to external facilities for sequencing after purification. DNA sequences were assembled and

255 edited using GENEIOUS and aligned with MAFFT v.6 using the G-INS algorithm and default

256 values for other parameters (Katoh \& Toh, 2008). To identify the corresponding supergroup of

257 Wolbachia we compared our sequences with previously classified sequenced according to Zhou,

258 Rousset \& O’Neill (1998), obtained from GenBank.

259

260 RESULTS

261 Combined phylogeny/phylogeography 
262 There were no length differences in the protein coding genes with the exception of $\mathrm{Wg}$, with

263 variation of a single AA in the ingroup. Length variation in the ribosomal genes ranged between

264 691-695 bp for the ingroup. The best partition scheme included a separation by codon position,

265 but the Bayesian analyses did not converge adequately due to insufficient data to estimate some

266 of the parameters, so we used the second best option, a partition by genes. The best evolutionary

267 models were GTR $+\mathrm{I}+\mathrm{G}$ for the COI-5', COI-3', 16S rRNA+tRNA-Leu and Wingless; GTR $+\mathrm{G}$

268 for nad1, and $\operatorname{Trn}+\mathrm{I}+\mathrm{G}$ for $\mathrm{H} 3$.

269 The ultrametric tree obtained with the combined mitocondrial and nuclear data showed a

270 topology compatible with that obtained in Garcia-Vazquez et al. (2016), with strong support for

271 the monophyly of all studied species groups but poorly resolved relationships within the western

272 clade (Fig. 2). In the D. aubei group we recovered the Pyrenean endemic D. delarouzei as

273 paraphyletic, at the base of the remaining species of the group, which monophyly was strongly

274 supported (Fig. 2). Within the later, the Sicilian and southern Italian D. semirufus were

275 monophyletic and sister to D. aubei plus D. semirufus from the northern Apennines (Tuscany

276 and Emilia-Romagna) and southeastern France. The Pyrenean D. aubei were paraphyletic at the

277 base of a strongly supported clade including first specimens from the Cevennes (geographically

278 closer) and then from the Alps Maritimes, Italian Alps and south Germany (Black Forest), plus

279 the Alpine D. semirufus (Fig. 2). The analysis of the mitochondrial data alone divided the $D$.

280 aubei group into two clades well separated geographically: one formed by specimens of $D$. aubei

281 aubei and D. semirufus from the Alps, Black Forest, French Massif Central and northern

282 Appenines, and the other clade subdivided into two sister groups, one formed by specimens of $D$.

283 delarouzei and D. aubei sanfilippoi from northern Spain and Pyrenees and the other by $D$.

284 semirufus from Sicily and central-southern Apennines. (See Fig. S1). Contrary to the results with

285 the combined or the mitochondrial data alone, the nuclear data recovered a monophyletic $D$.

286 aubei within a paraphyletic series including the other two species of the group (Fig. S2).

287 The species of the D. latus group were included in the eastern clade, as sister to the

288 species of the $D$. parvicollis group. Within the D. latus group, the Italian D. angelinii was sister

289 to the rest, which included the Iberian $D$. angusi and the widespread D. latus with the Turkish $D$.

290 toledoi nested within it (Fig. 2). Within the D. platynotus group, the two species of the group ( $D$.

291 platynotus and D. costipennis), and the subespecies D. c. costipennis, were respectively

292 monophyletic and well supported (Fig. 2). In the D. moestus group there was a deep intraspecific 
293 divergence in $D$. moestus. A clade with a predominantly western distribution included the

294 specimens from Morocco, southern Spain and southeastern France as sister to the Mallorcan

295 endemic $D$. brannani (Fig. 2). Its sister clade, with a predominantly eastern distribution, included

296 specimens of D. moestus from northern Spain to Bulgaria and with specimens of the two

297 previously recognised morphological subspecies (D. m. moestus and D. moestus inconspectus).

298 All species of the four studied groups were estimated to be of Pleistocene origin with the

299 exception of the deepest clades within the D. moestus complex, dated to the Pliocene-Pleistocene

300 boundary. Intraspecific variation was very recent (from the Upper Pleistocene), as was the

301 separation between some species, which have still not reached monophyly (e.g within the $D$.

302 latus or D. aubei groups) (Fig. 2).

303

304 Demographic models and detailed phylogeography

305 In all groups a strict molecular clock was preferred over the relaxed lognormal, which was 306 implemented in all analyses of demographic models (See Table 1 for AICM values). The run

307 with a relaxed lognormal clock in the $D$. latus group did not converge adequately despite running

308 for 100 million generations, especially for parameters of the 16S gene likely due to insufficient

309 variation. Exploratory analyses of the topology and divergent dates showed no substantial

310 variation with respect to the strict clock model, which was also adopted.

311 The coalescent analyses with logistic and expansion grow models did not converge

312 adequately in any group. The exponential grow model performed significantly better in the $D$.

313 platynotus group and the D. moestus complex, and the constant size model in the D. aubei group,

314 while there was no significant difference between both models in the D. latus group (Table 1).

315 The Bayesian skyline plot was very similar for the D. latus and $D$. aubei groups, with a nearly

316 constant effective population size with a recent, postglacial increase after a slight decline (Fig.

317 3). In the D. moestus complex it also remained constant until recent times, but with a recent

318 sharp decline followed by a fast increase recovering the previous effective population size. On

319 the contrary, in the D. platynotus group there was a gradual decrease ending in a sharp decline 320 (Fig. 3).

321 Due to the absence of outgroups in the phylogeographic analyses in BEAST the origin of 322 each of the individual clades was reconstructed in a position geographically intermediate

323 between the two basal nodes, and was not interpreted. 
In the $D$. aubei group there were three main lineages geographically well differentiated.

325 The north of the Iberian peninsula (Pyrenees and Cantabrian mountains) was reconstructed as

326 having been populated from east to the west by D. delarouzei and D. a. sanfilippoi; Sicily and

327 the central and southern part of the Italian peninsula by the southern D. semirufus; and the Alps

328 and nearby areas by D. a. aubei and the northern D. semirufus. Within the later, the expansion

329 seems to have been from the Alpes Maritimes and the Italian Piamonte to respectively the Massif

330 Central, the north side of the Alps, including the Black Forest, and the northern Apenines (see

331 Fig. 4 for the phylogenetic tree and Fig. 7 for the map with the phylogeographic reconstruction).

332 The reconstruction of the D. latus group showed an initial expansion into Italy at the

333 origin of $D$. angelinii. This initial expansion was followed first by the split between the eastern

334 D. toledoi (NE Turkey) and the remaining western lineages, with a second expansion including

335 the colonization of the Iberian peninsula by D. angusi and large areas of central and northern

336 Europe (including the British Islands) by D. latus (Figs 5,7). One of the sequenced specimens of

337 D. toledoi was, however, nested within D. latus (Fig. 5).

338 In the D. platynotus group the widespread D. platynotus originated in the Balkans, from

339 where expanded eastwards towards the Carpathians and northwards to reach central Europe (Figs 340 5,7).

341 The western clade of the D. moestus complex was reconstructed as having an origin

342 between the Balearic islands (with D. brannani) and north Morocco, from were it expanded

343 north to the rest of the Iberian peninsula and southern France. The eastern clade was

344 reconstructed as having an origin between the Tyrrhenian islands and southern Italy, from were

345 one lineage expanded to the north of the Iberian peninsula and north Italy up to Slovenia, and

346 another to Sicily, southern Italy and the Balkan peninsula (Greece and Bulgaria). The islands of

347 Corsica, Elba and Sicily had specimens of different origins within the eastern clade, but the

348 sampled Sardinian haplotypes had a single origin, with a back colonisation to Corsica (Figs 6,7).

349

350 Presence of Wolbachia

351 We did not detect Wolbachia in any of the eight tested specimens of the D. platynotus and $D$.

352 latus groups, with the only exception of one specimen of $D$. angelinii, positive for the

353 supergroup B of Wolbachia (Table S1). Within the western clade of the D. moestus group we did

354 not identify Wolbachia in any of the six specimens tested from Mallorca, Morocco and southern 
355 Spain, but the two tested specimens of D. moestus from Southern France were positive for

356 supergroup B. Of the 15 tested specimens of the eastern clade, three were positive for supergroup

357 A in the Pyrenees and northern Italy and four for supergroup B in Sicily and Greece. The three

358 tested specimens from the central Apenines and Elba were negative (Table S1).

359 Within the 25 tested specimens of the D. aubei group all were positive, with the only

360 exception of the six specimens of D. a. sanfilippoi from the Cantabrian Mountains, which were

361 negative. All the three tested specimens of D. a. sanfilippoi from the Pyrenees were, on the

362 contrary, infected. All infected populations of the group were positive for supergroup A, with the

363 exception of the two specimens from the French Massif Central and one isolated specimen of $D$.

364 semirufus from the Abruzzo, positive for supergroup B (Table S1).

366 DISCUSSION

\section{Recolonization process}

368 The species of Deronectes with a widespread European distribution have all an origin in the 369 southern Mediterranean peninsulas, in agreement with the common pattern of recolonisation 370 after the glacial cycles (Hewitt, 2000). However, there are some fundamental differences with

371 the standard models, as the distribution of the widespread species does not include the southern 372 peninsulas, which are occupied by vicariant taxa of recent origin. Thus, D. latus is replaced in 373 northern Anatolia by $D$. toledoi, in the Italian peninsula by $D$. angelini, and in the Iberian 374 Peninsula by $D$. angusi (Fig. 1). Within D. aubei the northern taxa (D. aubei aubei and the 375 northern clade of D. semirrufus) are restricted to south Germany, the Alps and the Massif 376 Central, being replaced in the north of the Iberian peninsula by D. aubei sanfilippoi and in 377 central and south Italy and Sicily by the southern clade of $D$. semirrufus. The situation with $D$. 378 platynotus and D. moestus is more complex, in the former due to the disjoint distribution, and in 379 the later due to unrecognised ancient diversity. However, in the Balkans D. platynotus only 380 reaches the northern mountain chains, in which populations present some morphological 381 differences that may warrant a taxonomic recognition (H. Fery, pers. comm. 2016). The 382 southernmost populations of the species, in north Greece, are considered a distinct subspecies 383 with a very restricted distribution, of which no specimens could be obtained for study ( $D$. 384 platynotus mazzoldii, Fery \& Brancucci, 1997). There is additional evidence that the species 385 currently restricted to Mediterranean peninsulas were never present in central and northern 
386 Europe, as there are no known records of Quaternary fossil remains of any of them (Abellán et 387 al., 2011).

388 The existence of these two partly non overlapping species pools (Mediterranean species 389 with ranges never extending to northern Europe, and northern species with limited southern 390 distributions) is consistent with increasing evidence from molecular studies of the role of the 391 Mediterranean peninsulas as a source of endemism (see e.g. Bilton et al., 1998; Petit et al., 2003; 392 Ribera \& Vogler, 2004). This suggests that after recolonisation during an ecologically optimal 393 period, northern populations become isolated from their source areas. At the end of each 394 Pleistocene Glacial cycle environmental conditions in the newly deglaciated areas in central and 395 north Europe could have been optimal for running water organisms typical of mountain streams, 396 such as Deronectes. The likely vast number of small streams from the thaw of the ice sheet, even 397 in lowland areas, could have represented an ecological opportunity for these species, favouring 398 range expansions to new empty areas without developed communities but with homogeneous 399 favourable conditions (Ribera et al., 2010). When ecological conditions changed populations 400 become increasingly isolated, resulting in the currently recognised taxa.

However, only some species in these lineages of poor dispersers expanded their ranges, 402 while the rest remained confined to restricted areas in the southern Peninsulas. The species with 403 widespread distributions do not seem to share any particular phylogenetic pattern. They are not 404 the oldest species in their clades, which could have lead to the hypothesis that their wider ranges 405 were due to a longer time to disperse (Willis, 1926; Gaston, 2003). On the contrary, they are in 406 most cases nested within southern species or populations. Another possibility is that their 407 physiological or ecological tolerances favoured their range expansion. There is some evidence 408 that differences in the ecological tolerance of the species are related to their geographic range 409 extent (Addo-Bediako, Chown \& Gaston, 2000; Gaston \& Spicer 2001; Gaston, 2009). Thus, 410 widespread species would have a higher ecological plasticity while species with restricted 411 distributions may have a limited physiological tolerance (West-Eberhard, 2003). Among the 412 many possible ecological or physiological factors, thermal tolerance have been frequently linked 413 with distributional ranges (e.g. Stillman, 2002; Somero, 2005; Verdú \& Lobo, 2008). Previous 414 physiological studies with Deronectes showed than widespread, more northerly distributed 415 species have broader thermal tolerance than their restricted southern relatives (Calosi, Bilton \& 416 Spicer, 2008; Calosi et al., 2010). Thus, the most widespread species of the genus, D. latus, had 
417 also the greatest thermal window (Calosi et al., 2010). However, there is a poor adjustment of

418 experimental data with ecological data derived from the localities they currently occupy

419 (Sánchez-Fernandez et al., 2012). With the available information (with no data on intraspecific

420 variability) is also not possible to assess if this wider thermal tolerance was previous to the range

421 expansion, making it possible, or if it was developed after the range expansion, as a consequence

422 of being exposed to a wider range of climatic conditions.

423 An alternative hypothesis is that the widespread species did not have any particular

424 physiological or ecological character favouring their range expansion, but just took advantage of

425 a privileged geographical position. They may have been the ones that happened to be at the edge

426 of the newly deglaciated areas. According to our results, populations in mountain ranges at the

427 northern edge of the southern peninsulas played a key role in the recolonization of glaciated

428 areas. Thus, the D. latus group is the westernmost lineage within the eastern Deronectes clade,

429 and the central European populations of D. platynotus appear nested within those of the northern

430 Balkans. Within the Iberian Peninsula, with numerous species of Deronectes with a restricted

431 distribution in most of its mountain systems (Millán et al., 2014; García-Vázquez et al., 2016),

432 the D. aubei group is restricted to the northernmost ranges (Cantabrian mountains and the

433 Pyrenean area, Fig. 1). As already noted, the situation within the D. moestus group is more

434 complex, due to the deep divergences between some lineages. Under this hypothesis, historical

435 more than intrinsic factors would determine which species become widespread and may be the

436 origin of further diversification (Ribera et al., 2011). The evidence supporting the role of

437 geographic position in facilitating range expansions relies on the assumption that southern

438 species have maintained their geographic ranges through the last glacial cycles, so that it is

439 possible to infer their past distribution from their current location. Although this assumption has

440 been challenged (e.g. Gaston 2003; Losos \& Glor, 2003), it has been repeatedly shown that in

441 poorly dispersing lineages range movements do not erase completely the geographic signal from

442 the past (Barraclough \& Vogler, 2000; Abellán \& Ribera, 2011; Ribera et al., 2011).

443

444 Demographic history of the recolonization

445 The dynamics of the range expansions was not the same in all the studied groups, as shown with

446 the reconstructions of the Bayesian skyline plots (Fig. 3). Thus, while in the D. aubei and D.

447 latus group we estimated a fast expansion through western Europe (D. aubei) or the whole 
448 continent (D. latus), leading to the current continuous distributions, in the D. platynotus group

449 there was a sharp decline in the effective population size, which may reflect their current

450 discontinuous distribution, with isolated populations in the east (D. platynotus) and the west (D.

451 costipennis). More difficult to interpret is the demographic history of D. moestus, with a sharp

452 decline corresponding roughly to the last Glacial Maximum (LGM) and a subsequent expansion.

453 In this complex, the late Pleistocene climatic cycles likely resulted in the isolation of the

454 different clades recovered in the phylogeny, some of which experienced subsequent expansions

455 when conditions improved after the LGM.

456

\section{Wolbachia infections}

458 We found a high prevalence of Wolbachia infection among Deronectes, with specimens infected

459 in five of the eleven studied species (45\%). This percentage is concordant with recent

460 estimations of a 40\% of Wolbachia prevalence among arthropods (Zug \& Hammerstein, 2012)

461 and $31 \%$ in a group of families of aquatic beetles, among them Dytiscidae, (Sontowsky et al.,

462 2015) thus making it the most successful endosymbiont on earth. As expected, all infected

463 specimens were for supergroups A and B, the most common in arthropods (Werren, Baldo \&

464 Clark, 2008).

465 The prevalence of Wolbachia was particularly high in the D. aubei group, in which all

466 sequenced populations were infected with the only exception of the Cantabrian Mountains, the

467 westernmost area of distribution of the group. It is interesting that this group had also a marked

468 contrast between the results of the mitochondrial and nuclear phylogenetic reconstructions,

469 although with the current data it is not possible to establish a clear link between the Wolbachia

470 infection and this discordance. Previous results, with a limited sampling, reported two

471 mitochondrial groups east and west of the Rhone river (García-Vázquez et al., 2016). This

472 scenario was modified with the inclusion of additional samples from the margins of the

473 distribution of the group, with the populations of D. semirrufus from Sicily and the central and

474 southern Apennines joining the Iberian and Pyrenean clade (including D. aubei sanfilippoi and

475 D. delarouzei), and the populations of $D$. aubei from the French Massif Central joining the

476 Alpine and German Black Forest clade (including D. semirrufus and D. aubei aubei). Thus, the

477 mitochondrial data separated the D. aubei group in two main lineages north and south of latitude

$47844^{\circ} \mathrm{N}$. On the contrary, nuclear data largely recovered monophyletic species, defined according to 
479 their external morphology and the male aedeagus (Fery \& Brancucci, 1997). In the mitochondrial

480 tree the two subspecies of $D$. aubei as defined with morphology were recovered in different

481 clades, with the only exception of the populations of the French Massif Central and the Cevennes

482 (west of the River Rhone), morphologically closer to the Pyrenean D. aubei sanfilippoi (Fery \&

483 Brancucci, 1997; H. Fery pers. comm., 2016) but grouped with D. aubei aubei from the Alps and

484 south Germany. In the evolutionary history of the $D$. aubei group there seem thus to be a first

485 event leading to mitochondrial introgression and geographic isolation within $D$. aubei and $D$.

486 semirrufus, separating in the former the recognised subspecies D. aubei sanfilippoi and D. aubei

$487 a u b e i$, and in the later the populations from Sicily and central and Southern Italy and those from

488 the Alps, which although not currently recognised as distinct taxa they have diagnostic

489 morphological differences (unpublished observations and H. Fery pers. comm., 2016).

490 Subsequent to this, there may have been a secondary event of introgression between the two

491 subspecies of D. aubei in the populations of the Massif Central and the Cevennes. These occupy

492 a geographically intermediate position between the western D. aubei sanfilippoi and the eastern

493 D. aubei aubei, with the general morphology of the former but a mitochondrial genome related

494 to the later.

495

496 ACKNOWLEDGEMENTS

497 We specially thank all collectors mentioned in Table S1 for their invaluable help in providing

498 material for the study, and R. Alonso and A. Izquierdo for laboratory work. We also thank D.T.

499 Bilton and L.F. Valladares for their help with the study of Deronectes.

500

\section{References}

502 Abellán P, Benetti CJ, Angus RB, Ribera I. 2011. A review of Quaternary range shifts in

503 European aquatic Coleoptera. Global Ecology and Biogeography 20:87-100.

504 Abellán P, Millán A, Ribera I. 2009. Parallel habitat-driven differences in the phylogeographical

505

506 structure of two independent lineages of Mediterranean saline water beetles. Molecular

507 Ecology 18:3885-3902.

508

509

Abellán P, Ribera I. 2011. Geographic location and phylogeny are the main determinants of the size of the geographical range in aquatic beetles. BMC Evolutionary Biology 11:344.

DOI: $10.1186 / 1471-2148-11-344$. 
510 Addo-Bediako A, Chown SL, Gaston KJ. 2000. Thermal tolerance, climatic variability and

511

512

513

514

515

516

517

518

519

520

521

522

523

524

525

526

527

528

529

530

531

532

533

534

535

536

537

538

539

540 latitude. Proceedings of the Royal Society B: Biological Sciences 267:739-745 DOI: 10.1098/rspb.2000.1065.

Andújar C, Serrano J, Gómez-Zurita J. 2012. Winding up the molecular clock in the genus Carabus (Coleoptera: Carabidae): assessment of methodological decisions on rate and node age estimation. BMC Evolutionary Biology 12:40.

Baele G, Lemey P, Bedford T, Rambaut A, Suchard MA, Alekseyenko AV. 2012. Improving the accuracy of demographic and molecular clock model comparison while accommodating phylogenetic uncertainty. Molecular Biology and Evolution 29:2157-2167.

Barraclough TG, Vogler AP. 2000. Detecting the geographical pattern of speciation from species-level phylogenies. The American Naturalist 155:419-434 DOI: 10.1086/303332.

Bielejec F, Rambaut A, Suchard MA, Lemey P. 2011. SPREAD: spatial phylogenetic reconstruction of evolutionary dynamics. Bioinformatics 27:2910-2912.

Bilton DT, Mirol PM, Mascheretti S, Fredga K, Zima J, Searle JB. 1998. Mediterranean Europe as an area of endemism for small mammals rather than a source for northwards postglacial colonization. Proceedings of the Royal Society B: Biological Sciences 265:1219-1226. DOI: 10.1098/rspb.1998.0423.

Böhning-Gaese K, Caprano T, van Ewijk K, Veith M. 2006. Range size: disentangling current traits and phylogenetic and biogeographic factors. The American Naturalist 167:555-567.

Brown JH. 1995. Macroecology. Chicago: University of Chicago Press.

Brown JH, Lomolino MV. 1998. Biogeography. Sunderland, MA: Sinauer.

Calosi P, Bilton DT, Spicer JI. 2008. Thermal tolerance, acclimatory capacity and vulnerability to global climate change. Biology Letters 4:99-102.

Calosi P, Bilton DT, Spicer JI, Votier SC, Atfield A. 2010. What determines a species' geographical range? Thermal biology and latitudinal range size relationships in European diving beetles (Coleoptera: Dytiscidae). Journal of Animal Ecology 79:194-204.

Dawson AG. 1992. Ice age earth: Late Quaternary geology and climate. New York: Routledge. Dijkstra KDB, Monaghan MT, Pauls SU. 2014. Freshwater biodiversity and aquatic insect diversification. Annual Review of Entomology 59:143-163.

Drummond AJ, Rambaut A. 2007. BEAST: Bayesian evolutionary analysis by sampling trees. BMC Evolutionary Biology 7: 214. 
541 Fery H, Brancucci M. 1997. A taxonomic revision of Deronectes SHARP, 1882 (Insecta:

542

543

544

545

546

547

548

549

550

551

552

553

554

555

556

557

558

559

560

561

562

563

564

565

566

567

568

569

570 Coleoptera: Dytiscidae) (part I). Annalen des Naturhistorischen Museums in Wien. Serie B für Botanik und Zoologie 99:217-302.

García-Vázquez D, Bilton DT, Alonso R, Benetti CJ, Garrido J, Valladares LF, Ribera I. 2016. Reconstructing ancient Mediterranean crossroads in Deronectes diving beetles. Journal of Biogeography DOI: 10.1111/jbi.12740

Gaston KJ. 2003. The structure and dynamics of geographic ranges. Oxford: Oxford University Press.

Gaston KJ. 2009. Geographic range limits of species. Proceedings of the Royal Society B: Biological Sciences 276:1391-1534.

Gaston KJ, Spicer JI. 2001. The relationship between range size and niche breadth: a test using five species of Gammarus (Amphipoda). Global Ecology and Biogeography 10:179-188.

Hansen TA. 1980. Influence of larval dispersal and geographic distribution on species longevity in neogastropods. Paleobiology 6:193-207.

Hebert PD, Ratnasingham S, de Waard JR. 2003. Barcoding animal life: cytochrome c oxidase subunit 1 divergences among closely related species. Proceedings of the Royal Society B: Biological Sciences 270:S96-S99.

Hewitt G. 2000. The genetic legacy of the Quaternary ice ages. Nature 405:907-913.

Homburg K, Drees C, Gossner MM, Rakosy L, Vrezec A, Assmann T. 2013. Multiple glacial refugia of the low-dispersal ground beetle Carabus irregularis: molecular data support predictions of species distribution models. PloS ONE 8:e61185.

Jablonski D. 1987. Heritability at the species level - Analysis of geographic ranges of Cretaceous molluscs. Science 238:360-363. DOI: 10.1126/science.238.4825.360.

Jiggins FM. 2003. Male-killing Wolbachia and mitochondrial DNA: selective sweeps, hybrid introgression and parasite population dynamics. Genetics 164:5-12.

Katoh K, Toh H. 2008. Recent developments in the MAFFT multiple sequence alignment program. Briefings in bioinformatics 9:286-298.

Lanfear R, Calcott B, Ho SY, Guindon S. 2012. PartitionFinder: combined selection of partitioning schemes and substitution models for phylogenetic analyses. Molecular Biology and Evolution 29:1695-1701. 
571 Lemey P, Rambaut A, Drummond AJ, Suchard MA. 2009. Bayesian phylogeography finds its $572 \quad$ roots. PLoS Computational Biology 5:e1000520.

573 Lester SE, Ruttenberg BI, Gaines SD, Kinlan BP. 2007. The relationship between dispersal

574

575 ability and geographic range size. Ecology Letters 10:745-758. DOI: 10.1111/j.1461-

576 0248.2007.01070.x.

577

Losos JB, Glor RE. 2003. Phylogenetic comparative methods and the geography of speciation.

578

579

580

581

582

583

584

585

586

587

588

589

590

591

592

593

594

595

596

597

598

599

600

601 Trends in Ecology and Evolution 18:220-227. DOI: 10.1016/S0169-5347(03)00037-5.

Millán A, Sánchez-Fernández D, Abellán P, Picazo F, Carbonell JA, Lobo JM, Ribera I. 2014. Atlas de los coleópteros acuáticos en la España peninsular. Madrid: Ministerio de Agricultura, Alimentación y Medio Ambiente, Centro de Publicaciones.

Nilsson AN. 2001. World catalogue of insects. Volume 3: Dytiscidae (Coleoptera). Stenstrup: Apollo Books.

Nilsson AN, Hájek J. 2015. Catalogue of Palearctic Dytiscidae (Coleoptera). Update distributed as a PDF file via Internet; version 1. I. 2015. Available at: http://www2.emg.umu.se/projects/biginst/andersn/PAL_CAT_2015.pdf

Petit RJ, Aguinagalde I, de Beaulieu JL, Bittkau C, Brewer S, Cheddadi R, Ennos R, Fineschi S, Grivet D, Lascoux M. 2003. Glacial refugia: hotspots but not melting pots of genetic diversity. Science 300:1563-1565.

Purvis A, Gittleman JL, Cowlishaw G, Mace GM. 2000. Predicting extinction risk in declining species. Proceedings of the Royal Society of London B: Biological Sciences 267:19471952.

Ribera I. 2003. Are Iberian endemics Iberian? A case-study using water beetles of family Dytiscidae (Coleoptera). Graellsia 59:475-502.

Ribera I. 2008. Habitat constraints and the generation of diversity in freshwater macroinvertebrates. In: Lancaster J, Briers RA (eds.) Aquatic Insects: Challenges to Populations. CAB International, 289-311.

Ribera I, Barraclough TG, Vogler AP. 2001. The effect of habitat type on speciation rates and range movements in aquatic beetles: inferences from species-level phylogenies. Molecular Ecology 10:721-735.

Ribera I, Castro A, Díaz JA, Garrido J, Izquierdo A, Jäch MA, Valladares LF. 2011. The geography of speciation in narrow-range endemics of the "Haenydra" lineage 
602

603

604

605

606

607

608

609

610

611

612

613

614

615

616

617

618

619

620

621

622

623

624

625

626

627

628

629

630

(Coleoptera, Hydraenidae, Hydraena). Journal of Biogeography 38:502-516. DOI:

10.1111/j.1365-2699.2010.02417.x.

Ribera I, Vogler AP. 2000. Habitat type as a determinant of species range sizes: the example of lotic-lentic differences in aquatic Coleoptera. Biological Journal of the Linnean Society 71: 35-52.

Ribera I, Vogler AP. 2004. Speciation of Iberian diving beetles in Pleistocene refugia (Coleoptera, Dytiscidae). Molecular Ecology 13:179-193.

Rosenfield JA. 2002. Pattern and process in the geographical ranges of freshwater fishes. Global Ecology and Biogeography 11:323-332.

Sánchez-Fernández D, Aragón P, Bilton DT, Lobo JM. 2012. Assessing the congruence of thermal niche estimations derived from distribution and physiological data. A test using diving beetles. PLoS ONE 7:e48163.

Somero GN. 2005. Linking biogeography to physiology: evolutionary and acclimatory adjustments of thermal limits. Frontiers in zoology 2:1.

Sontowski R, Bernhard D, Bleidorn C, Schlegel M, Gerth M. 2015. Wolbachia distribution in selected beetle taxa characterized by PCR screens and MLST data. Ecology and Evolution 5:4345-4353.

Stevens GC. 1989. The latitudinal gradient in geographical range: How so many species coexist in the tropics. The American Naturalist 133:240-256. DOI: 10.1086/284913.

Stillman JH. 2002. Causes and consequences of thermal tolerance limits in rocky intertidal porcelain crabs, genus Petrolisthes. Integrative and Comparative Biology 42:790-796.

Verdú JR, Lobo JM. 2008. Ecophysiology of thermoregulation in endothermic dung beetles: ecological and geographical implications. In Fattorini S (ed) Insect Ecology and Conservation. Research Signpost, 1-28.

Werren JH, Baldo L, Clark ME. 2008. Wolbachia: master manipulators of invertebrate biology. Nature Reviews Microbiology 6:741-751.

West-Eberhard MJ. 2003. Developmental plasticity and evolution. Oxford: Oxford University Press.

Willis JC. 1926. Age and area. The Quarterly Review of Biology 1:553-571. 
631 Zhou W, Rousset F, O’Neill S. 1998. Phylogeny and PCR-based classification of Wolbachia 632 strains using wsp gene sequences. Proceedings of the Royal Society of London B:

633 Biological Sciences 265:509-515.

634 Zug R, Hammerstein P. 2012. Still a host of hosts for Wolbachia: analysis of recent data suggests 635 that $40 \%$ of terrestrial arthropod species are infected. PloS ONE 7:e38544.

636

637 


\section{FIGURE LEGENDS}

639

640 Figure 1. Known distribution of the species of the four studied groups of Deronectes. White 641 circles, sampled localities.

642

643 Figure 2. Ultrametric tree obtained with BEAST with the combined nuclear and mitochondrial

644 sequence and a partition by gene. The tree had an arbitrary root distance, but the scale is adjusted 645 to the age of the basal node obtained with the mitochondrial tree (Fig. S1). Numbers on nodes, 646 Bayesian posterior probabilities. See Table S1 for details on the specimens and localities.

647 Habitus photograph, D. latus (from Lech Borowiec,

648 http://www.colpolon.biol.uni.wroc.pl/index.htm).

649

650 Figure 3. Bayesian Skyline plots for each species group of the analyses of the mitochondrial 651 sequence, assuming a strict clock (see Methods for details). Thin lines, 95\% confidence intervals; 652 horizontal axis, time (MY); vertical axis, effective population size (NeT).

653

654 Figure 4. Ultrametric time calibrated tree obtained with BEAST with the combined nuclear and 655 mitochondrial sequence of all sampled specimens of the $D$. aubei group, using the coordinates of 656 each locality as a quantitative trait and the best population coalescent model for each group.

657 Numbers on nodes, Bayesian posterior probabilities. See Fig. 7 for a graphic representation of 658 the reconstructed geographical coordinates, and Table S1 for details on the specimens and 659 localities. 
661 Figure 5. Ultrametric time calibrated trees obtained with BEAST with the combined nuclear and

662 mitochondrial sequence of all sampled specimens of (1) the D. latus group and (2) the D.

663 platynotus group, using the coordinates of each locality as a quantitative trait and the best

664 population coalescent model for each group. Numbers on nodes, Bayesian posterior probabilities.

665 See Fig. 7 for a graphic representation of the reconstructed geographical coordinates, and Table

666 S1 for details on the specimens and localities.

667

668 Figure 6. Ultrametric time calibrated tree obtained with BEAST with the combined nuclear and

669 mitochondrial sequence of all sampled specimens of the D. moestus complex, using the

670 coordinates of each locality as a quantitative trait and the best population coalescent model for

671 each group. Numbers on nodes, Bayesian posterior probabilities. See Fig. 7 for a graphic

672 representation of the reconstructed geographical coordinates, and Table S1 for details on the

673 specimens and localities.

674

675 Figure 7. Phylogeographic reconstruction through time in Google Earth

676 (http://earth.google.com) of the history of each lineage, from the origin until the current

677 distribution, based on the results represented in Figs 4-6. Parabolas represent the reconstructed

678 displacements between nodes in the phylogeny (in red, basal nodes). Yellow arrows mark the

679 general direction of the range expansions, and the white dashed line the hypothesized area of

680 origin of each group. (1) D. aubei group; (2) D. latus group; (3) D. platynotus group; (4) D.

681 moestus complex. Photo credit: Image Landsat, IBCAO and U.S. Geological Survey. Data SIO,

682 NOAA, U.S. Navy, NGA, GEBCO.

683

684 


\section{Table $\mathbf{1}$ (on next page)}

Model selection

Analyses of the best molecular clock model and population coalescent model for each group, including AICM values and standard error (SE). In bold, best AICM value for each pair. Differences below 2 were not considered as significant. 
1

2 Table 1. Analyses of the best molecular clock model and population coalescent model for each

3 group, including AICM values and standard error (SE). In bold, best AICM value for each pair.

4 Differences below 2 were not considered as significant. The relaxed model for $D$. latus failed to

5 converge and was not considered (see Results).

6

7

\begin{tabular}{llcclcc} 
& clock & \multicolumn{5}{c}{ coalescence } \\
group & model & AICM & SE & model & AICM & SE \\
\hline D. aubei & relaxed & 8235 & $+/-0.33$ & constant & $\mathbf{8 1 9 6}$ & $+/-0.27$ \\
& strict & $\mathbf{8 1 9 6}$ & $+/-0.13$ & exponential & 8199 & $+/-0.28$ \\
D. latus & relaxed & - & - & constant & 7274 & $+/-0.09$ \\
& strict & $\mathbf{7 2 7 4}$ & $+/-0.09$ & exponential & 7274 & $+/-0.22$ \\
& relaxed & 8734 & $+/-0.30$ & constant & 8720 & $+/-0.25$ \\
D. moestus & strict & $\mathbf{8 7 2 0}$ & $+/-0.15$ & exponential & $\mathbf{8 7 1 6}$ & $+/-0.16$ \\
& relaxed & 7052 & $+/-0.04$ & constant & 7049 & $+/-0.07$ \\
D. platynotus & strict & $\mathbf{7 0 4 9}$ & $+/-0.18$ & exponential & $\mathbf{7 0 4 6}$ & $+/-0.07$
\end{tabular}

8 


\section{Figure 1 (on next page)}

Distribution maps of the studied species

Known distribution of the species of the four studied groups of Deronectes. Black circles, sampled localities. 


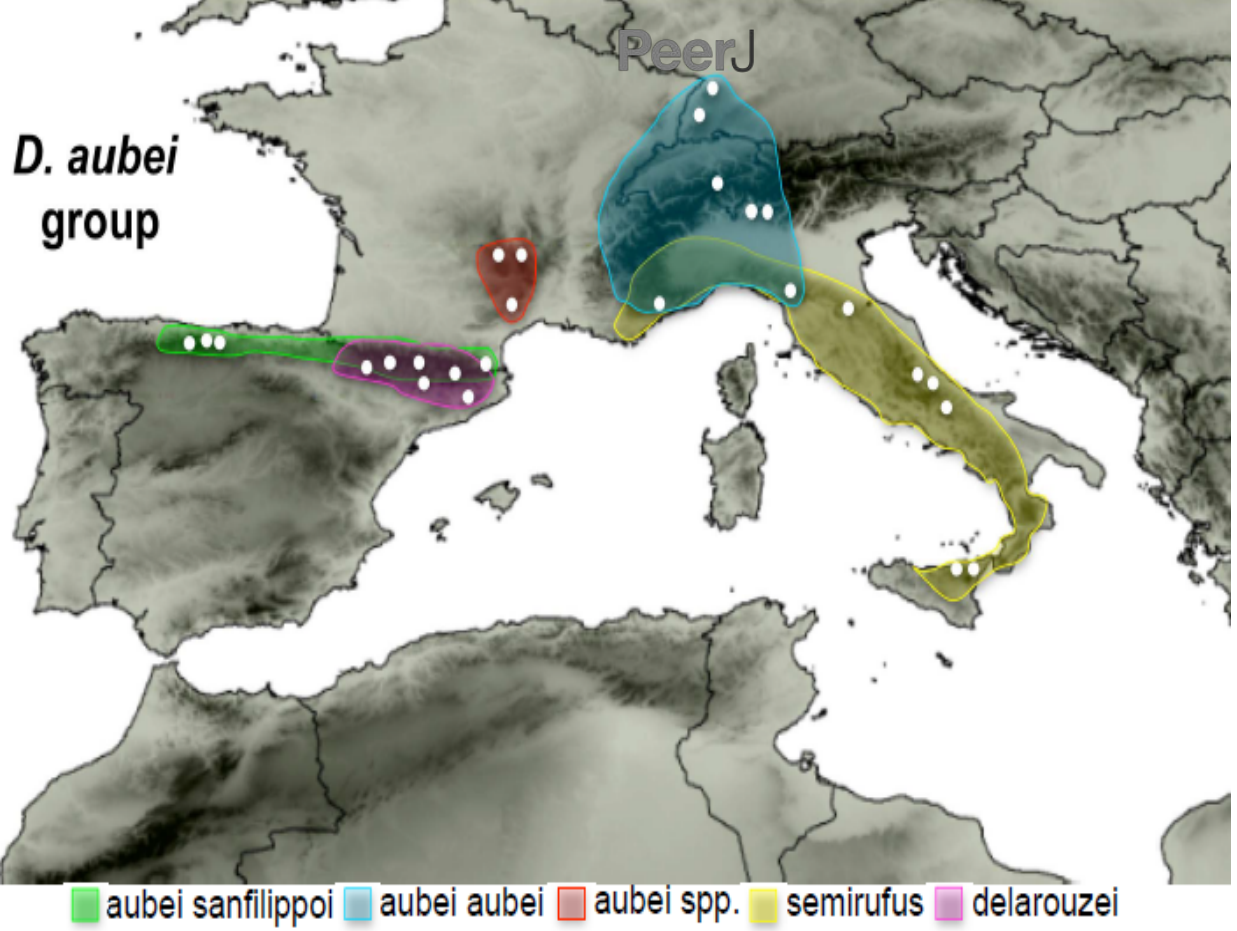


Figure 2 (on next page)

Phylogenetic tree of the studied groups of Deronectes

Ultrametric tree obtained with BEAST with the combined nuclear and mitochondrial sequence and a partition by gene. The tree had an arbitrary root distance, but the scale is adjusted to the age of the basal node obtained with the mitochondrial tree (Fig. S1). Numbers on nodes, Bayesian posterior probabilities. See Table S1 for details on the specimens and localities. Habitus photograph, D. latus (from Lech Borowiec, http://www.colpolon.biol.uni.wroc.pl/index.htm). 


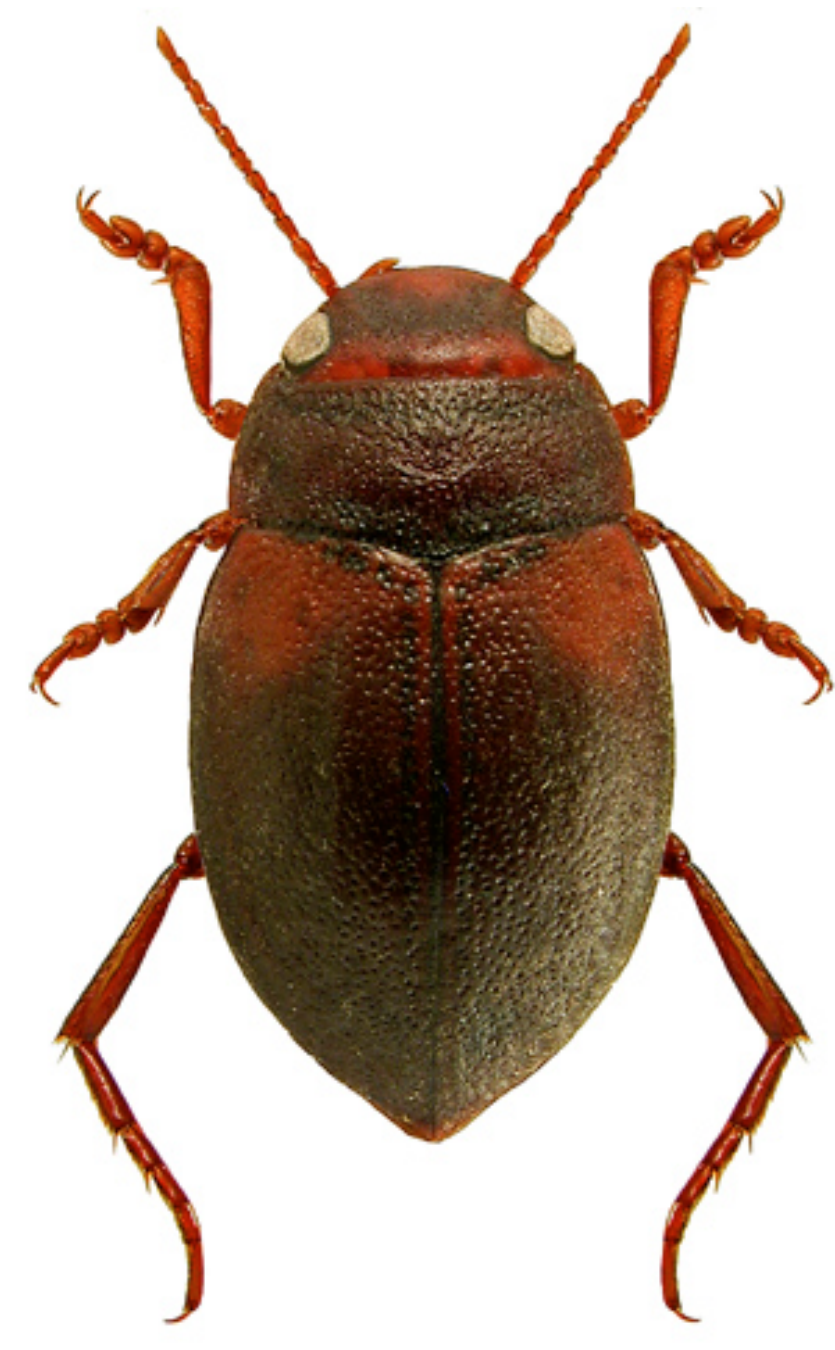

PeerJ (5)

${ }_{52}\left[\begin{array}{l}0.68 \\ \text { aubei s. DV23_ESPNNO15 }\end{array}\right.$ aubei s. DV110_ESPNNO16 aubei s. DV13 ESPNNO12 aubeis. DV9 ESPNNO10

0.99 प 1 a

aubei s. DV11_ESPNNO11 semirufus RA427_ITACN5 1 semirufus DV59_ITACN1 semirufus AH178_ISIC3 H 11 semirufios DN24_eICA semirufies DVP4_EICIC4
semirus DV117_ISIC1 [ delarouzei DV135_ESPPIR15 delarouzei Al1071_ESPPIR2 de.71 delarouzei DV159_ESPPIR20 delarouzei DV201_ESPPIR18 5. delarouzei DV175_ESPPIR21 1 delarouzei DV98_ESPPIR7 delarouzei DV107_ESPPIR12 delarouzei DV1_ESPPIR10 opatrinus Al629

hispanicus Al858 depressicollis Al1023 fosteri IR77

1 ferrugineus Al731 wewalkai AI725
algibensis IR76 bicostatus Al639 moestus i. DV188_ESPEST4 moestus i. DV94_ITACN5 moestus i. RA333_CRO1 $\left[\begin{array}{l}\text { moestus i. Al1048_ITAN2 } \\ \text { moestus i. RA338_ESPPIR7 }\end{array}\right.$ moestus m. DV72_ICER4 $\left[\begin{array}{l}\text { moestus } \\ \text { moestus } m \text {. DV41_ICER1 }\end{array}\right.$ moestus m. DV66_ICER2 moestus i. DV62_IELBA1 $L_{1}{ }_{\text {moestus }}$ m. DV69_ICER3 1 moestus i. DV142_ESPPIR17 moestus i. DV180_ESPPIR22 moestus i. DV79_ESPPIR6

moestus i. RA331_ESPPIR5 moestus i. DV178_ESPPIR21 $\left[\begin{array}{l}\text { moestus i. DV178_ESPPIR21 } \\ \text { moestus i. DV203_ESPPIR19 }\end{array}\right.$ moestus i. DV53_GRE1 $0.97\left[\begin{array}{l}0.74 \\ \text { moestus i. Al672_BUL1 }\end{array}\right.$ $0.89[$ moestus i. DV55_GRE2 1 moestus i. DV64 GRE3 LOSUS I. DVA_GRE3 moestus i. DV118_ISIC2 0.94
moestus i. DV118_ISIC2
moestus i. DV205_ISIC6 moestus i. RA365_MARATL9 moestus i. Al894_ESPSUR2 1. moestus i. Al937 MARATL1 mostu I. DVI28 ESPSURT - moestus i. RA374_FRAE4 brannanii Al178_IMALL1 $\left[\begin{array}{l}0.39 \\ \text { brannanii DV40_IMALL2 }\end{array}\right.$ brannanii DV74_IMALL3 - fairmairei DV43 theryi RA37 - lareynii IR165 platynotus Al1039_BUL3 platynotus Al1121_MAC1 - platynotus DV213_RUM1 0.99 platynotus Al1122_ALE1 platynotus DV137_ALE2 - platynotus RA335_MAC2 costipennis c. Al183_PORCN1 $[1$ costipennis C. DV155 PORCN8 costipennis g. DV19_ESPNNO13 - sahlbergi Al108 doriae Al775

PeerJ reviewing PDF | (2016:06:1 1288:1:0:NEW 11 Aug 2016) latus DV80_ESL2 [ [ $\left[\begin{array}{l}0.68 \\ \text { latus RA343_ESL1 }\end{array}\right.$ latus DV77_CRO2 0.89 latus DV189_ALE5
0.96 latus RA412_ENG1 latus DV182_ALE6 latus DV112_SCO1 $[-9.95$ latus DV45_BUL3 0.98 latus Al137 MON1 - angusi DV67_ESPNNO17 angusi RA443_ESPNNO6 angusi RA443_ESPNNNO6 - persicus IR45 parvicollis Al776 nilssoni AF104 0.0 


\section{Figure 3 (on next page)}

Demographic history of the studied groups of Deronectes.

Bayesian Skyline plots for each species group of the analyses of the mitochondrial sequence, assuming a strict clock (see Methods for details). Thin lines, 95\% confidence intervals; horizontal axis, time (MY); vertical axis, effective population size (NeT). 


\section{Figure 4(on next page)}

Ultrametric time calibrated tree of the $D$. aubei group

Ultrametric time calibrated tree obtained with BEAST with the combined nuclear and mitochondrial sequence of all sampled specimens of the $D$. aubei group, using the coordinates of each locality as a quantitative trait and the best population coalescent model for each group. Numbers on nodes, Bayesian posterior probabilities. See Fig. 7 for a graphic representation of the reconstructed geographical coordinates, and Table S1 for details on the specimens and localities. 
aubei sanfilippoi DV26_ESPNNO16

aubei sanfilippoi DV103_ESPNNO14

aubei sanfilippoi DV110_ESPNNO16

aubei sanfilippoi DV25_ESPNNO15

aubei sanfilippoi DV109_ESPNNO15

aubei sanfilippoi DV13_ESPNNO12

aubei sanfilippoi DV108_ESPNNO15

aubei sanfilippoi DV97_ESPNNO11

aubei sanfilippoi DV21_ESPNNO14

a.7 aubei sanfilippoi DV20_ESPNNO14

aubei sanfilippoi DV23_ESPNNO15

aubei sanfilippoi ER41_ESPNNO3

aubei sanfilippoi DV12_ESPNNO1 aubei sanfilippoi DV9_ESPNNO10

1 aubei sanfilippoi DV11_ESPNNO11

0.94 aubei sanfilippoi DV10_ESPNNO10

delarouzei RA337_ESPPIR7

0.86

delarouzei DV98_ESPPIR7

delarouzei DV202_ESPPIR18 0.92

0.67 delarouzei DV201_ESPPIR18 delarouzei DV175_ESPPIR21

delarouzei DV192_ESPPIR21 0.78

delarouzei DV191_ESPPIR21

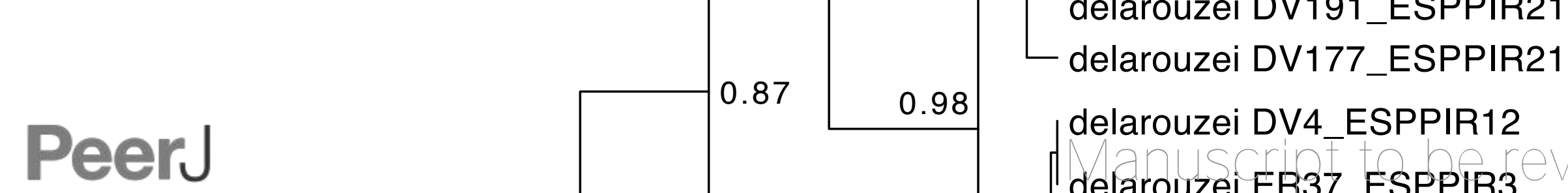

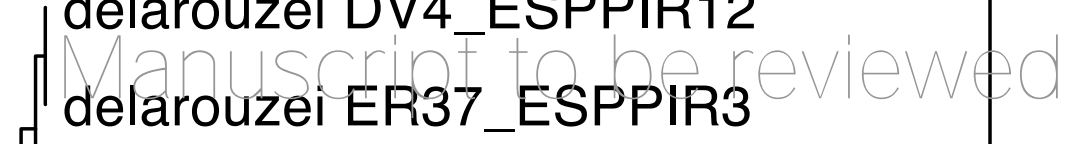

delarouzei DV107_ESPPIR12

delarouzei AF85_ESPPIR1

- delarouzei DV1_ESPPIR10

delarouzei R78_ESPPIR4

delarouzei DV3_ESPPIR12

0.76 delarouzei DV5_ESPPIR13

delarouzei DV159_ESPPIR20

0.93 delarouzei DV135_ESPPIR15

0.74 Lelarouzei Al1071_ESPPIR2

- aubei sanfilippoi DV261_FRAO1 aubei sanfilippoi DV101_ESPPIR14

1 aubei sanfilippoi DV15_ESPPIR14

0.98 aubei sanfilippoi DV209_FRAO1

0.62 - aubei sanfilippoi DV14_ESPPIR14

delarouzei DV2_ESPPIR10 aubei aubei DV139_ALE3 0.94

aubei aubei DV138_ALE3

aubei aubei DV145 ALE4

aubei aubei DV171_ALE3

Germany

aubei aubei RA139_ITAN7

[aubei aubei DV150_ITAN7

$0.88 \quad \begin{array}{r}1 \text { aubei aubei DV150_ITAN7 } \\ \text { aubei aubei IR304_SU11 } \\ \text { semirufus DV51_FRAE1 }\end{array}$

$0.88 \quad \begin{array}{r}1 \\ \text { aubei aubei IR304_SUI1 } \\ \text { semirufus DV51_FRAE1 }\end{array}$

$0.99 \int_{\text {semirufus IR299_FRAE2 }}^{0.5}$

0.99 semirufus DV131_FRAE1

aubei aubei IR300_FRAE3

Alps

aubei aubei Al1211_ITAN3

- aubei aubei DV165_ITAN7 semirufus DV90_ITACN3 0.99

semirufus DV88_ITACN3

semirufus RA417 ITACN4 semirufus DV91_ITACN4

1 semirufus DV89 ITACN3 0.58 RA418_ITACN semirufus RA418 ITACN4 semirufus DV93_ITACN4 semirufus DV33_ITAN1 0.95

0.94 semirufus AF94_ITAN1

semirufus RA136_ITAN6

aubei aubei RA135_ITAN5 aubei spp. DV140_FRAO3 1

aubei spp. DV141_FRAO3

aubei spp. DV160_FRAO4 [aubei spp. DV162_FRAO4

aubei spp. DV164_FRAO4 aubei spp. DV149_FRAO2 0.98 . aubei spp. RA122_FRAO2 aubei spp. DV148_FRAO2 semirufus DV35_ISIC4 0.68 .

semirufus DV34_ISIC4

1 semirufus RA340 ISIC7

semirufus AH178_ISIC3 semirufus AC33_ISIC1

1 semirufus DV30_ISIC

semirufus DV117_ISIC1

semirufus DV100_ITACN6

Massif

Central

(France)

semirufus RA450_ITACN6

semirufus DV99_ITACN6

[semirufus RA427_ITACN5 
Figure $\mathbf{5}$ (on next page)

Ultrametric time calibrated trees of the $D$. latus and $D$. platynotus groups

Ultrametric time calibrated trees obtained with BEAST with the combined nuclear and mitochondrial sequence of all sampled specimens of (1) the $D$. latus group and (2) the $D$. platynotus group, using the coordinates of each locality as a quantitative trait and the best population coalescent model for each group. Numbers on nodes, Bayesian posterior probabilities. See Fig. 7 for a graphic representation of the reconstructed geographical coordinates, and Table S1 for details on the specimens and localities. 


\section{PeerJ}

\section{D. latus group}

0.97 [latus DV80_ESL2 latus DV78_CRO2 0.64

latus RA343_ESL1

I latus DV77_CRO2 0.98

0.83 latus RA345_CRO2

toledoi DV7_TUR3 |

latus RA412_ENG1

$-0.98$

latus RA413_ENG1

0.6- latus DV189_ALE5

0.98 Latus IR137_ENG1

[ latus DV184_ALE6

0.66

latus DV182_ALE6

0.88

[ latus RA350_ESL2

0.68 latus DV82_ESL2

Llatus Al1038_BUL3

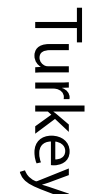

$$
\text { ֻ }
$$

兄. $\frac{\text { D }}{\frac{D}{3}}$

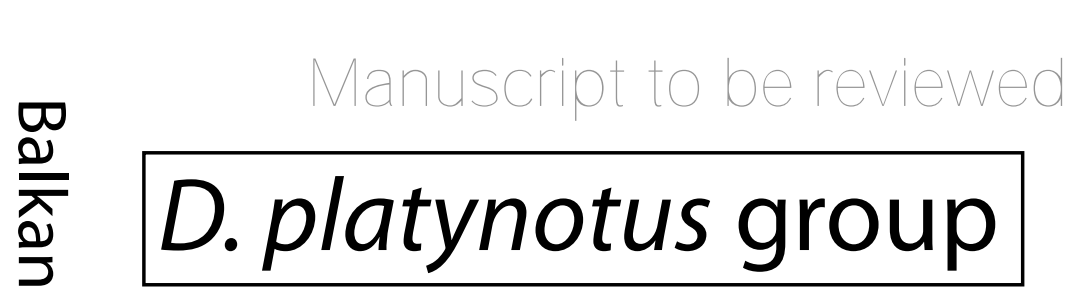

platynotus

Al1275_RCHE1

platynotus

DV137_ALE2

platynotus

DV213_RUM1

$\int^{0.43}$ latus DV112_sCO1

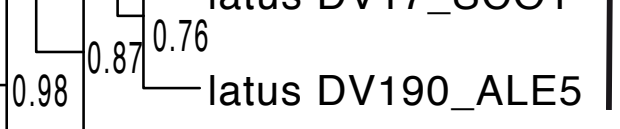
latus DV17_SCO1

— latus Al137_MON1

latus DV45_BUL3

黾

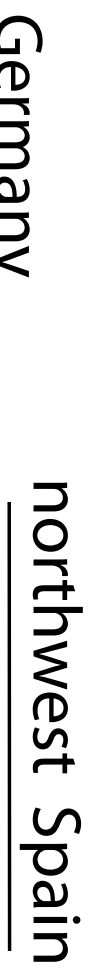

angusi RA443_ESPNNO6 0.75

angusi DV68_ESPNNO17 0.72

angusi DV67_ESPNNO17 angusi IR253_ESPNNO4 angusi Al1273_ESPNNO2 toledoi DV8_TUR3

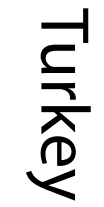
toledoi DV6_TUR3 定
NW Iberian Peninsula platynotus

RA316_MON2

platynotus

Al1121_MAC1

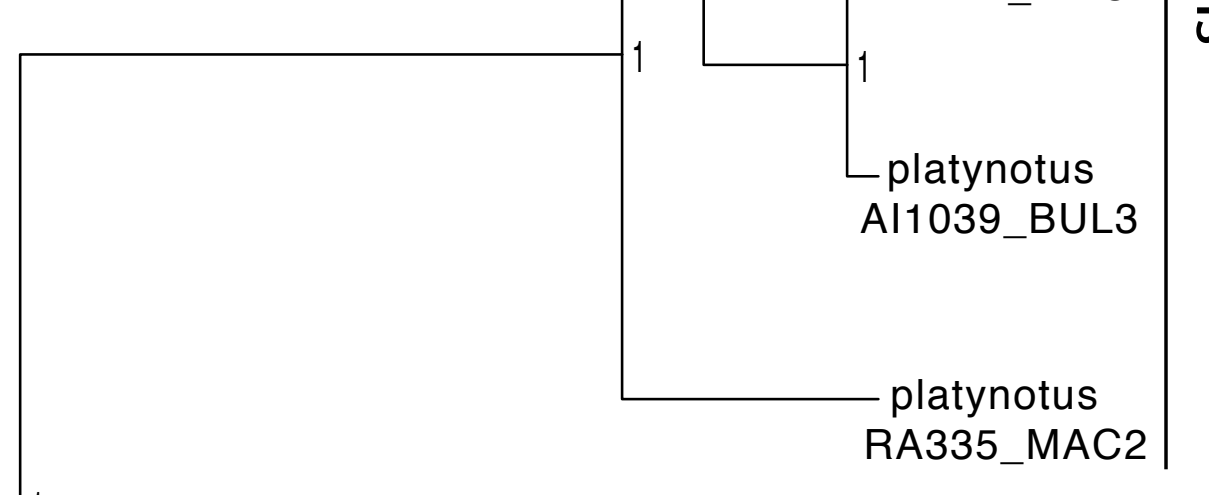

costipennis $\mathrm{g}$.

[DV19_ESPNNO13 1

costipennis C.

ER40_ESPNNO3

costipennis C.

[DV155_PORCN8

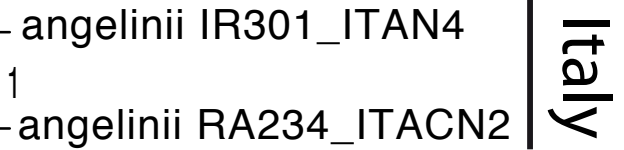

costipennis C. Al183_PORCN1 


\section{Figure 6 (on next page)}

Ultrametric time calibrated tree of the $D$. moestus complex

Ultrametric time calibrated tree obtained with BEAST with the combined nuclear and mitochondrial sequence of all sampled specimens of the $D$. moestus complex, using the coordinates of each locality as a quantitative trait and the best population coalescent model for each group. Numbers on nodes, Bayesian posterior probabilities. See Fig. 7 for a graphic representation of the reconstructed geographical coordinates, and Table S1 for details on the specimens and localities. 
0.96 |moestus moestus DV73_ICER4

moestus moestus DV72_ICER4 moestus moestus DV41_ICER1 0.92 moestus moestus DV122

0.910 .88 moestus moestus DV122_ICER1 moestus moestus DV66_ICER2

0.88 moestus moestus DV166_ICER4 , moestus moestus LMsB_ICOR3 O.91 $m$ moestus moestus DV70_ICER3 0.88
moestus moestus DV69_ICER3

moestus moestus DV71_ICER3 moestus moestus RA307_ICER2 0.99

0.96
moestus moestus RA310 ICER3 .87 0.88 moestus inconspectus DV62_IELBA1

D. moestus moestus inconspectus DV48_ITAN2 0.97 moestus inconspectus Al1048_ITAN2 - moestus inconspectus RA333_CRO1 0.88 moestus inconspectus IR303_ITAN4 moestus inconspectus DV94_ITACN5 moestus inconspectus RA429_ITACN5 moestus inconspectus DV95_ITACN5 moestus inconspectus DV193_ESPPIR21

0.890 .88 mostus incon 0.87 moesthenintion

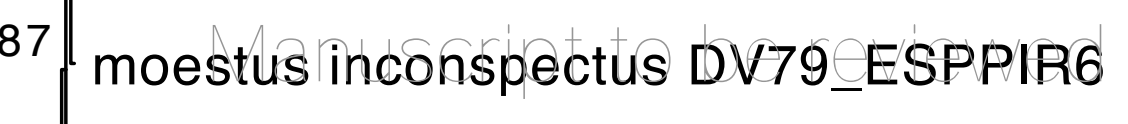

PeerJ 0.97 moestus inconspectus DV194_ESPPIR22 0.89 moestus inconspectus DV195_ESPPIR22

moestus inconspectus DV179_ESPPIR21 moestus inconspectus DV142_ESPPIR17 oestus inconspectus RA338_ESPPIR7 moestus inconspectus DV187_ESPPIR17 moestus inconspectus DV143 ESPPIR17

87 moestus inconspectus DV181_ESPPIR22 moestus inconspectus DV180_ESPPIR22 moestus inconspectus DV186_ESPPIR17 .88 L moestus inconspectus RA331_ESPPIR5 moestus inconspectus DV188_ESPEST4 0.98 mostus inconspectus DV18__ESPEST4 0.98

4 moestus inconspectus DV147 ESPEST4 moestus inconspectus IR82_ESPPIR4 moestus inconspectus DV203_ESPPIR19 $1 \mid \begin{array}{ll}0.91 \\ \text { moest }\end{array}$

1 moestus inconspectus DV196_ESPPIR22 moestus inconspectus DV199_ESPPIR17 moestus inconspectus DV64_GRE3 moestus inconspectus RA213_GRE3 0.9
moestus inconspectus DV65 GRE3 moestus inconspectus Al1218 GRE2 moestus inconspectus DV132_GRE2 moestus inconspectus DV55_GRE2 moestus inconspectus Al672_BUL1 moestus inconspectus DV53 GRE1 mestus inconspectus DV53_GRE1 moestus inconspectus DV206_ISIC6 99 moestus inconspectus DV31_ISIC2 moestus inconspectus DV119_ISIC2 1 moestus inconspectus DV63_IELBA1 moestus inconspectus RA145_IELBA1 Elba moestus inconspectus DV118_ISIC2 | moestus inconspectus DV263_ISIC2 0.92
moestus inconspectus AC37_ISIC2 0.96

moestus inconspectus DV208_ISIC6

moestus inconspectus DV205_ISIC6 moestus moestus IR156_ICOR1| Corsica moestus inconspectus DV129_ESPSUR14 moestus inconspectus DV128_ESPSUR14

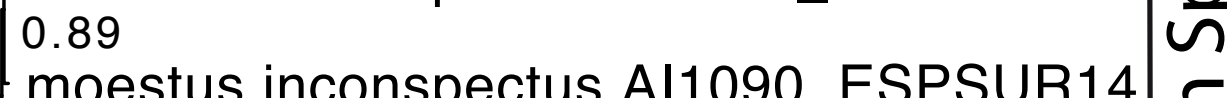
0.88 . moestus inconspectus IR207_ESPSUR5 moestus inconspectus Al894_ESPSUR2 moestus inconspectus A1937_MARATL1 0.96

moestus inconspectus DW235_MARATL4

- moestus inconspectus RA365_MARATL9 moestus inconspectus DV87_FRAE4

moestus inconspectus RA374_FRAE4

moestus inconspectus DV86_FRAE4 岃 brannanii DV40_IMALL2 brannanii Al296_IMALL2 brannanii DV75_IMALL3 brannanii DV38_IMALL1 brannanii DV38_IMALL1 
Figure 7 (on next page)

Phylogeographic reconstruction of the history of each lineage

Phylogeographic reconstruction through time in Google Earth ( http://earth.google.com ) of the history of each lineage, from the origin until the current distribution, based on the results represented in Figs 4-6. Parabolas represent the reconstructed displacements between nodes in the phylogeny (in red, basal nodes). Yellow arrows mark the general direction of the range expansions, and the white dashed line the hypothesized area of origin of each group. (1) $D$. aubei group; (2) D. latus group; (3) D. platynotus group; (4) D. moestus complex. Photo credit: Image Landsat, IBCAO and U.S. Geological Survey. Data SIO, NOAA, U.S. Navy, NGA, GEBCO. 


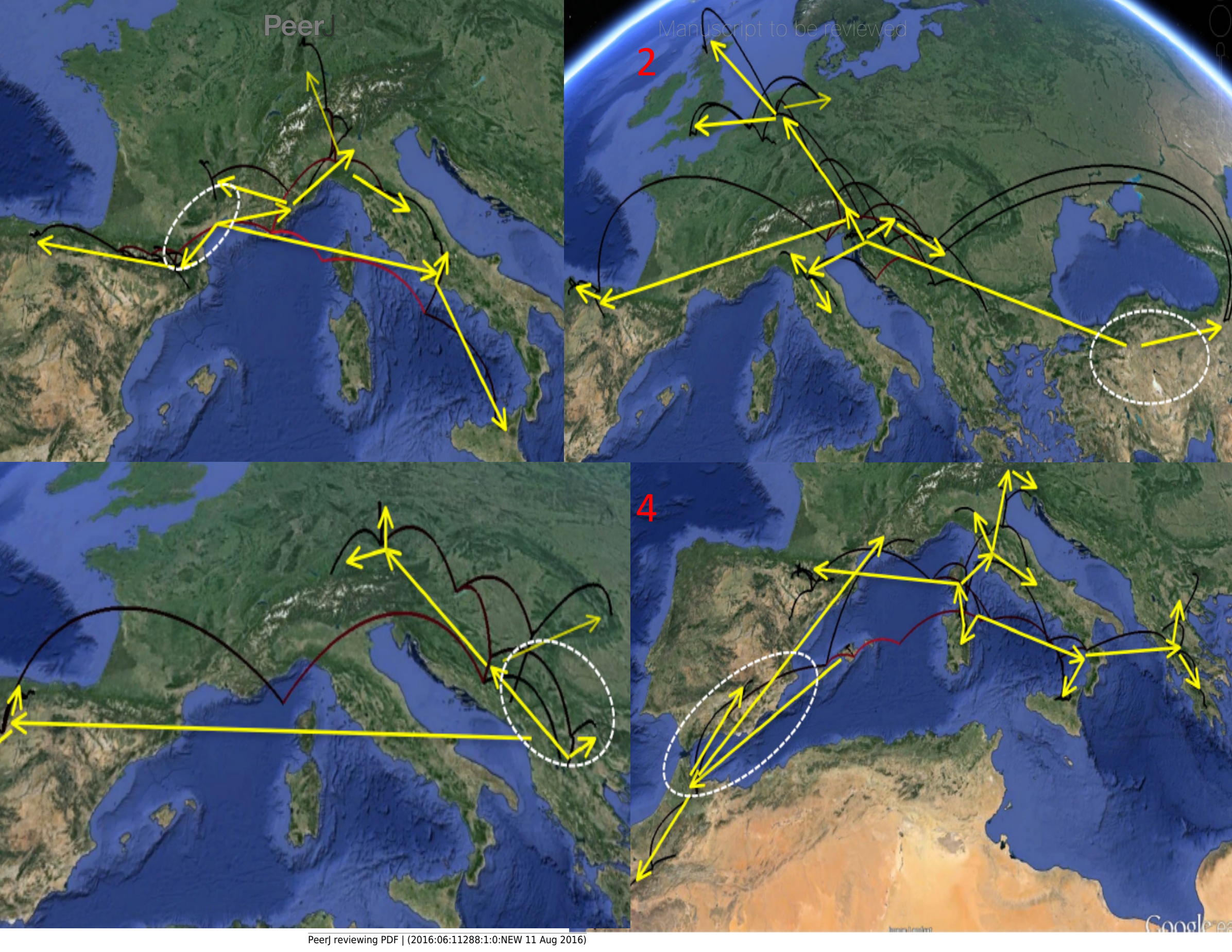

